\title{
Levantamento de espécies epífitas vasculares da zona urbana do município de Palmeira das Missões, RS, Brasil
}

\author{
A survey of vascular epiphyte species of the urban area of \\ Palmeira das Missões, RS, Brazil
}

\author{
Maria Elenice de Oliveira Alves $\stackrel{1}{\text {, Clediane Brun }{ }^{2} \text { Raquel Sulzbach Dal Forno }}{ }^{3}$, Liliana Essi ${ }^{4}$ \\ 1,2,3 Graduandas, Departamento de Biologia, Universidade Federal de Santa Maria, \\ Palmeira das Missões, RS, Brasil, \\ ${ }^{4}$ Professora adjunta do Departamento de Biologia, Departamento de Biologia, \\ Universidade Federal de Santa Maria, Santa Maria, Brasil
}

\begin{abstract}
Resumo
Parques e praças arborizados são refúgios da natureza nas áreas urbanas, os quais contribuem para a conservação da biodiversidade, funcionando, muitas vezes, como pequenos corredores ecológicos. A presença de certas espécies epífitas na zona urbana auxilia na avaliação da qualidade ambiental tanto da cidade quanto do seu entorno. Foi realizado um levantamento qualitativo de espécies epifitas vasculares na zona urbana do município de Palmeira das Missões, Rio Grande do Sul, incluindo as principais praças, o Parque Municipal de Exposições da cidade e o campus da Universidade Federal de Santa Maria. Foram encontradas oito espécies de angiospermas e seis espécies de pteridófitas, em sua maioria espécies de amplo espectro ecológico. Uma espécie rara para o estado foi registrada no estudo. Tais resultados representam uma contribuição ao conhecimento da biodiversidade vegetal em áreas urbanas e fragmentos florestais da região norte do Rio Grande do Sul.
\end{abstract}

Palavras-chave: Epifitismo. Fragmentos florestais. Diversidade vegetal,

\begin{abstract}
Wooded parks and squares are refuges of nature in urban areas, which contribute to the conservation of biodiversity, working frequently as small ecological corridors. The presence of certain epiphytic species in the urban area assists in the evaluation of the environmental quality of both the city and its surroundings. We conducted a qualitative survey of species vascular epiphytes in urban areas of Palmeira das Missões, Rio Grande do Sul State, including the main squares, the Municipal Park and the campus of the Universidade Federal de Santa Maria. We found eight species of angiosperms and six species of pteridophytes, mostly species of broad ecological spectrum. A rare species in the State was recorded in the study. These results represent a contribution to knowledge of plant biodiversity in urban areas and forest fragments in the Northern of Rio Grande do Sul.
\end{abstract}




\section{Introdução}

O epifitismo, segundo DISLICH (1996), é a forma de relação característica das plantas que se desenvolvem sobre outras sem prejudicá-las. Dezenas de famílias de plantas apresentam representantes epífitos, porém a existência de táxons adaptados especificamente para a vida no dossel superior é restrita a poucas famílias, particularmente Araceae, Bromeliaceae, Cactaceae, Gesneriaceae e Orchidaceae (BENNET, 1986). Dentre as epífitas vasculares mais comuns nos levantamentos da flora epifítica no sul do Brasil, destacam-se algumas famílias de angiospermas (Bromeliaceae, Orchidaceae) e de pteridófitas (Polypodiaceae). Conforme BENZING (1990), as epífitas são representadas por aproximadamente 23.500 espécies, pertencentes a 84 famílias e 876 gêneros. Baseando-se nesse e outros levantamentos, DISLICH (1996) conclui que cerca de $10 \%$ das espécies de plantas vasculares são epífitas.

A distribuição das espécies epifíticas sobre os forófitos relaciona-se ao tipo de substrato que este proporciona (BUZATTO et al., 2008), e também às variações de luminosidade e umidade estabelecidas entre o dossel e à concentração de $\mathrm{CO} 2$ disponível no ambiente (KERSTEN \& SILVA, 2001). A frequência dos epífitos vasculares sobre diferentes indivíduos forofíticos está relacionada a fatores intrínsecos destes, tais como tamanho, idade, arquitetura da árvore e características da casca, ou a adaptações da própria espécie epifítica (BENZING, 1990). No Brasil existem relativamente poucos estudos que tratam da composição florística e da distribuição espacial de epífitas vasculares, a grande maioria realizada nas regiões Sul e Sudeste (GERALDINO et al., 2010; KERSTEN \& SILVA, 2001; BUZATTO et al., 2008; KERSTEN \& KUNIYOSHI., 2009; KERSTEN, 2010; BERNARDI \& BUDKE, 2009; GONÇALVES \& WAECHTER, 2003; BUZATTO et al., 2007; BAUER \& WAECHTER, 2006 e GIONGO \& WAECHTER, 2004).

No estado do Rio Grande do Sul (RS), uma das primeiras regiões em que os ecossistemas naturais foram mais rapidamente degradados foi a região norte. A área ocupada pelo município de Palmeira das Missões era recoberta por uma extensa e fechada mata nativa. Logo nos primeiros anos de colonização, houve uma grande extração de madeira que mudou a paisagem original (ARDENGHI, 2003). Atualmente, as formações florestais são representadas por pequenos fragmentos de mata entre lavouras, em especial em áreas de mata ciliar. $\mathrm{O}$ município situa-se em uma área de contato entre duas formações fitogeográficas do RS ocorrentes na região do Alto Uruguai: a Floresta Estacional Decidual e a Floresta Ombrófila Mista (Figura 1). Estes dois tipos florestais sofreram, ao longo do tempo, desmatamentos devido à implementação de culturas agrícolas (COSTA, 2010). Estes remanescentes florestais ainda abrigam grande diversidade biológica, tanto na zona rural como na zona urbana do município, e embora os fragmentos não sejam áreas tão adequadas para a conservação da biodiversidade, dado o forte efeito de borda, têm um papel decisivo como corredores ecológicos, permitindo que organismos se desloquem ou seus diásporos sejam dispersos para áreas próximas. Alguns estudos importantes têm sido realizados em fragmentos florestais no Alto Uruguai (BERNARDI \& BUDKE, 2009; LONGHI, 1997; VACCARO \& LONGHI, 1995; COSTA, 2010; SCIPIONI et al., 2011), porém com ênfase no componente arbóreo. Poucos estudos vêm sendo realizados sobre o componente epifítico de fragmentos ou em áreas urbanas no estado, tais como o estudo de GONÇALVES \& WAECHTER (2003), BATAGHIN et al. (2008) e ainda não há estudos sobre o componente epifítico de fragmentos ou da área urbana no município de Palmeira das Missões.

O presente trabalho visa realizar um levantamento florístico do componente epifítico vascular presente em árvores da zona urbana do município de Palmeira das Missões, como uma contribuição para o conhecimento da flora regional e da diversidade ocorrente em áreas urbanas e fragmentos florestais.

\section{Material e métodos}

O levantamento de espécies epífitas foi realizado por meio de coletas quinzenais, no campus da UFSM, no Parque Municipal de Exposições e em três praças do município de Palmeira das Missões, RS, ao longo de dez meses, a contar de março a dezembro de 2012. Para as coletas no campus e no parque de exposições, foi utilizado o método de caminhamento (FILGUEIRAS et al., 1994) adaptado, onde foram percorridas linhas horizontais imaginárias em busca de espécimes arbóreos, seguida da escalada do forófito para acessar os epífitos, quando visualizados do solo. Nas áreas menores (praças), os epífitos de todos os forófitos encontrados foram registrados. A observação de epífitos vasculares foi realizada a partir do solo em todas as áreas, e quando se fez necessário foi realizada escalada natural do forófito.

O material testemunho foi coletado em fenofase reprodutiva, para preparo de exsicatas e adequada identificação. A preparação de exsicatas do material coletado seguiu as recomendações de FIDALGO \& BONONI (1984). As espécies foram identificadas com auxílio de chaves analíticas presentes em literatura especializada e os exemplares foram incluídos no herbário SMDB, sendo guardada uma duplicata no campus de Palmeira das Missões, sempre que possível. A coleta de material testemunho foi realizada sempre que a espécie era registrada pela primeira vez no estudo. Registros posteriores foram fotográficos ou através de anotações no caderno de campo, com identificação no local.

Para o estudo da distribuição vertical dos epífitos, os forófitos foram divididos em três estratos: fuste baixo (até 1,5 $\mathrm{m}$ do solo), fuste alto (de 1,5 $\mathrm{m}$ do solo até a base da copa) e copa, nas quais foram registradas todas as 


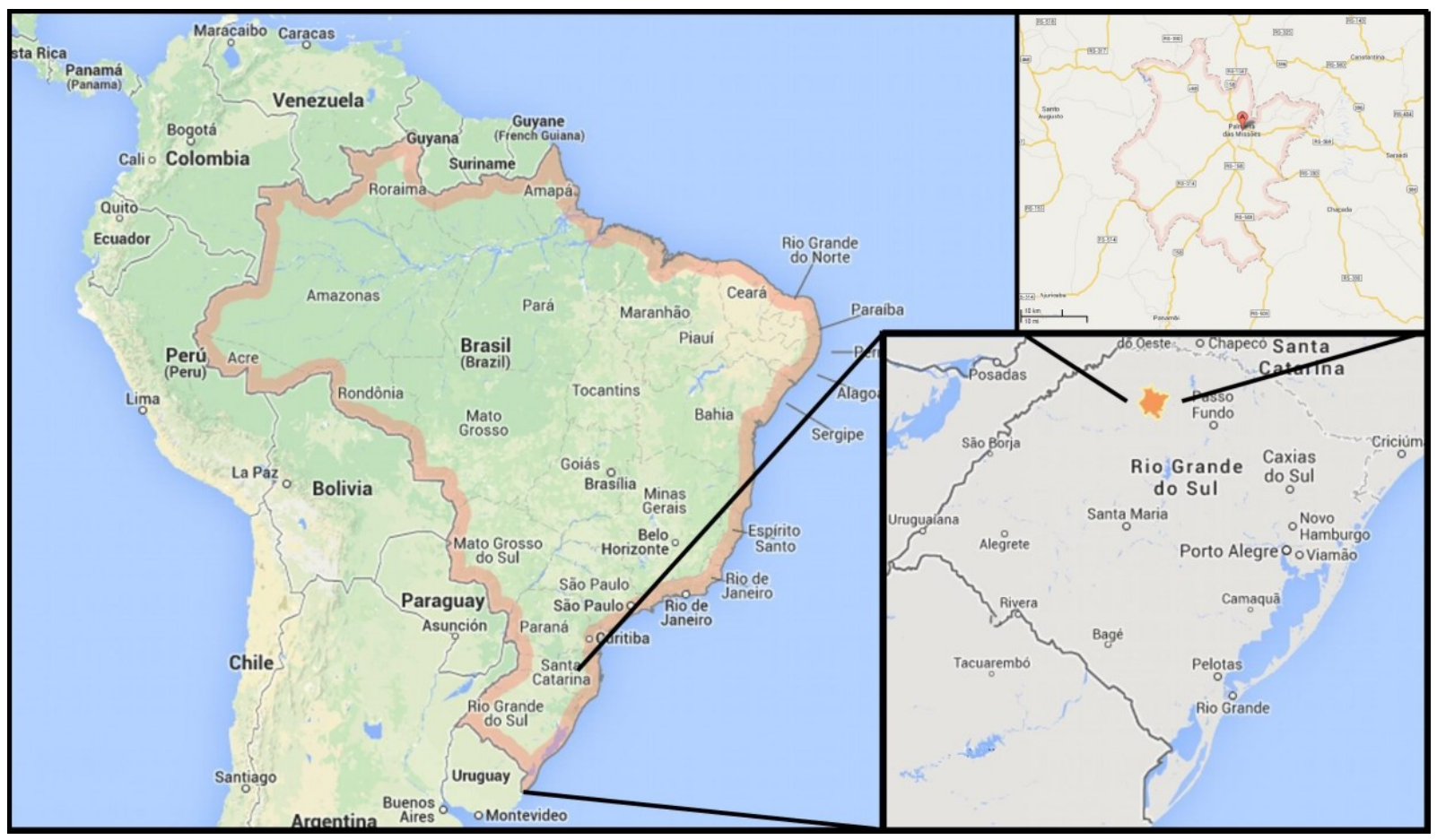

Figura 1: Localização do Município de Palmeira das Missões, RS, Brasil (mapa adaptado do site Google maps).

espécies epifíticas ocorrentes.

As espécies registradas foram classificadas em cinco categorias ecológicas, de acordo com sua relação com o forófito (BENZING, 1990), que são: holoepífito característico (plantas que em nenhum período de sua vida possuem contato com o solo), holoepífito facultativo (plantas que crescem sobre o solo ou em árvores), holoepífito acidental (plantas que apesar de não possuir nenhuma adaptação para o hábito epifítico, podem, crescer sobre outros vegetais), hemiepífito primário (espécies que germinam sobre os forófitos e posteriormente estabelecem contato com o solo), hemiepífito secundário (espécies que germinam no solo e depois constituem contato com um forófito, perdendo a ligação com o solo).

\section{Resultados e discussão}

Foram confirmadas 14 espécies pertencentes a 10 gêneros, sendo as seguintes:

Aechmea recurvata (Klotzsch) L. B. Sm. (Figura 2 E), Campyloneurum nitidum (Kauf.) C. Presl., Coppensia bifolia (Sims) Dumort (Figura 2 F), Coppensia flexuosa (Sims) Campacci, Lepismium lumbricoides (Lem.) Barthlott (Figura 2 A), Microgramma squamulosa (Kaulf.) de la Sota, Monstera deliciosa Liebm., Philodendron bipinnatifidum Schott ex Endl. (Figura 2 D), Pleopeltis hirsutissima (Raddi) de la Sota, Pleopeltis pleopeltifolia (Raddi) Alston, Pleopeltis squalida (Vell.) de la Sota (Vell.), Rumohra adiantiformis (G. Forst.) Ching (Figura 2 B)., Tillandsia recurvata (L.) L. e Tillandsia stricta Sol. ex Sims. (Figura 2 C).

Destas, seis espécies pertencem a famílias de pteridófitas, e oito pertencem a famílias de angiosper- mas. A família com maior número de representantes é Polypodiaceae, com cinco representantes, em seguida Bromeliaceae com três representantes e Orchidaceae e Araceae com duas espécies cada. As demais famílias apresentaram um representante cada. O número de espécies por família seguiu um padrão observado em outros estudos realizados no RS, com espécies concentradas em poucas famílias (WAECHTER, 1992; BUZATTO et al., 2008; BERNARDI \& BUDKE, 2009).

As espécies que foram encontradas em todos os locais de coleta foram: Lepismium lumbricoides, Microgramma squamulosa, Pleopeltis pleopeltifolia, P. squalida, Tillandsia recurvata e T. stricta. Campyloneurum nitidum foi encontrada apenas no campus e no Parque Municipal de Exposições. Já as espécies Aechmea recurvata, Coppensia bifolia, Monstera deliciosa, Philodendron bipinnatifidum e Rumohra adiantiformis foram registradas somente no campus e Coppensia flexuosa estava presente em apenas uma das praças amostradas.

Com relação à distribuição das epífitas nos forófitos, observou-se que as mesmas distribuem-se de forma irregular ao longo do forófito, apresentando variação vertical, tanto no número de indivíduos como de espécies encontradas, conforme também encontrado por WAECHTER (1992, 1998). Muitas espécies tiveram sua ocorrência restrita ao fuste médio e alto e poucas no fuste baixo (Tabela 1). Apenas três espécies são indiferentes, ocorrendo nos três estratos (FB, FM e CP), as quais também se destacaram por ocorrem em todos os pontos de coleta: M. squamulosa, T. recurvata, T. stricta, e P. pleopeltifolia.

Na posição inferior do fuste ocorreram sete espécies, enquanto que 13 distribuíram-se na porção superior do 

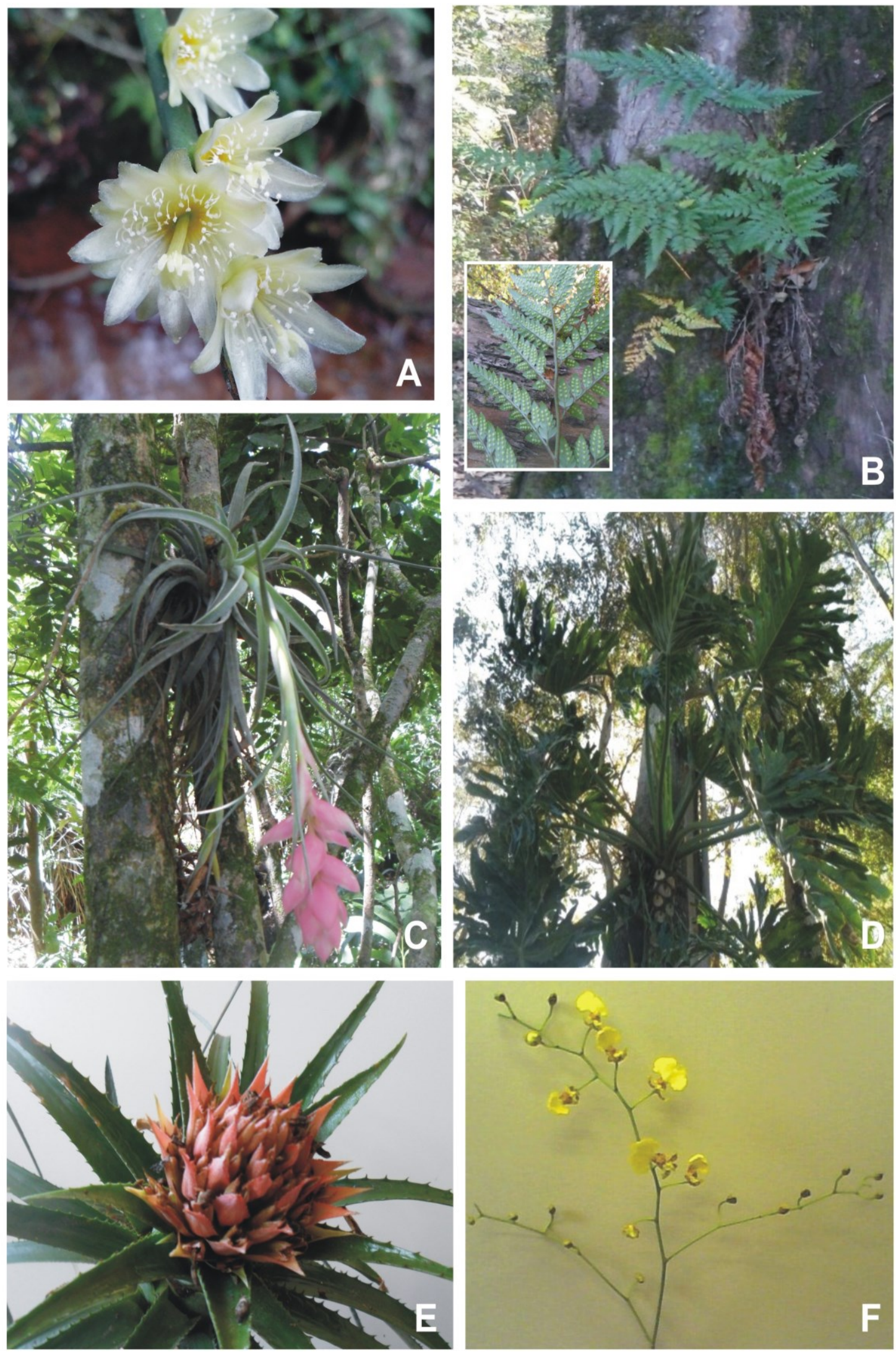

Figura 2. A. Lepismium lumbricoides (Lem.) Barthlott: detalhe da flor; B. Rumohra adiantiformis (G.Forst.) Ching.: hábito e detalhe dos sori; C. Tillandsia stricta Sol. Ex Sims: hábito; D. Philodendron bipinnatifidum Schott ex Endl.: hábito; E. Aechmea recurvata (Klotzsch) L. B. Sm.: detalhe da inflorescência; F. Coppensia bifolia (Sims) Dumort.: ramo da inflorescência. 
Tabela 1. Epífitas vasculares e forófitos associados. As espécies registradas são apresentadas por famílias, indicando-se na coluna à direita as espécies de forófitos onde os epífitos foram localizados. Apresenta-se, também, o tamanho das populações (Número de epífitos observados em um raio de 5 metros - N), a classificação da distribuição vertical (DV) do epífito nos forófitos (fuste baixo- FB, fuste médio- FM e copa - CP), e as categorias ecológicas (CE) dos epífitos registrados (holoepífita verdadeira HLV, holoepífita facultativa HLF, hemiepífita secundária HMS).

\begin{tabular}{|c|c|c|c|c|}
\hline $\begin{array}{l}\text { FAMÍLIA } \\
\text { Espécie de epífito }\end{array}$ & Espécie de forófito & $\mathbf{N}^{*}$ & DV & $\mathrm{CE}$ \\
\hline $\begin{array}{l}\text { ARACEAE } \\
\text { Monstera deliciosa }\end{array}$ & $\begin{array}{l}\text { Syagrus romanzoffiana (Cham.) } \\
\text { Glassman (Jerivá) }\end{array}$ & 1 & FM & HMS \\
\hline $\begin{array}{l}\text { ARACEAE } \\
\text { Philodendron } \\
\text { bipinnatifidum }\end{array}$ & $\begin{array}{l}\text { Eucalyptus grandis W. Hill } \\
\text { (Eucalipto) } \\
\text { Lagerstroemia indica L. (Flor- } \\
\text { de-natal) }\end{array}$ & $\begin{array}{c}1-5 \\
1\end{array}$ & FB, FM & HMS \\
\hline $\begin{array}{l}\text { BROMELIACEAE } \\
\text { Aechmea recurvata }\end{array}$ & $\begin{array}{l}\text { Erythrina crista-galli L. } \\
\text { (Corticeira-do-banhado) } \\
\text { Luehea divaricata Mart. } \\
\text { (Açoita-cavalo) }\end{array}$ & $\begin{array}{c}6-10 \\
1\end{array}$ & FM & HLF \\
\hline $\begin{array}{l}\text { BROMELIACEAE } \\
\text { Tillandsia recurvata }\end{array}$ & $\begin{array}{l}\text { Handroanthus chrysotrichus } \\
\text { (Mart. Ex A. DC.) Mattos (Ipê } \\
\text { amarelo) } \\
\text { Matayba guianensis Aubl. } \\
\text { (Camboatá-branco) }\end{array}$ & $6-10$ & $\begin{array}{l}\mathrm{FB}, \mathrm{FM}, \\
\mathrm{CP}\end{array}$ & HLV \\
\hline $\begin{array}{l}\text { BROMELIACEAE } \\
\text { Tillandsia stricta }\end{array}$ & $\begin{array}{l}\text { Peltophorum dubium (Spreng.) } \\
\text { Taub. (Canafístula) } \\
\text { Araucaria angustifolia } \\
\text { (Bertol.) Kuntze (Pinheiro-do- } \\
\text { paraná) }\end{array}$ & $\begin{array}{l}6-10 \\
6-10\end{array}$ & $\begin{array}{l}\text { FB, FM, } \\
\text { CP }\end{array}$ & HLV \\
\hline $\begin{array}{l}\text { CACTACEAE } \\
\text { Lepismium lumbricoides }\end{array}$ & $\begin{array}{l}\text { Tipuana tipa Lillo (Tipa) } \\
\text { Enterolobium contortisiliquum } \\
\text { (Vell.) Morong (Timbaúva) }\end{array}$ & $\begin{array}{c}>20 \\
1\end{array}$ & $\mathrm{FM}, \mathrm{CP}$ & HLV \\
\hline $\begin{array}{l}\text { DRYOPTERIDACEAE } \\
\text { Rumohra adiantiformis }\end{array}$ & Eucalyptus sp. (Eucalipto) & 1 & FB & HLF \\
\hline $\begin{array}{l}\text { ORCHIDACEAE } \\
\text { Coppensia bifolia }\end{array}$ & E. grandis (Eucalipto) & 1 & FM & HLF \\
\hline $\begin{array}{l}\text { ORCHIDACEAE } \\
\text { Coppensia flexuosa }\end{array}$ & $\begin{array}{l}\text { Ligustrum lucidum W. T. Aiton } \\
\text { (Alfeneiro) }\end{array}$ & $1-5$ & FM & HLF \\
\hline $\begin{array}{l}\text { POLYPODIACEAE } \\
\text { Campyloneurum } \\
\text { nitidum }\end{array}$ & $\begin{array}{l}\text { Cupania vernalis Cambess. } \\
\text { (Camboatá -vermelho) } \\
\text { Parapiptadenia rigida (Benth.) } \\
\text { Brenan (Angico) }\end{array}$ & $\begin{array}{l}1-5 \\
6-10\end{array}$ & FB, FM & HLF \\
\hline $\begin{array}{l}\text { POLYPODIACEAE } \\
\text { Microgramma } \\
\text { squamulosa }\end{array}$ & $\begin{array}{l}\text { P. dubium (Canafístula) } \\
\text { Cedrella fissilis (Cedro) }\end{array}$ & $\begin{array}{l}>20 \\
1-5\end{array}$ & $\begin{array}{l}\text { FB, FM, } \\
\text { CP }\end{array}$ & HLV \\
\hline
\end{tabular}


Tabela 1. continuação...

\begin{tabular}{|c|c|c|c|c|}
\hline $\begin{array}{l}\text { FAMÍLIA } \\
\text { Espécie de epífito }\end{array}$ & Espécie de forófito & $\mathbf{N}^{*}$ & DV & $\mathrm{CE}$ \\
\hline $\begin{array}{l}\text { POLYPODIACEAE } \\
\text { Pleopeltis hirsutissima }\end{array}$ & $\begin{array}{l}\text { Eucalyptus sp. (Eucalipto) } \\
\text { Jacaranda mimosifolia D. Don } \\
\text { (Jacarandá) }\end{array}$ & $\begin{array}{l}1-5 \\
1-5\end{array}$ & FM & HLV \\
\hline $\begin{array}{l}\text { POLYPODIACEAE } \\
\text { Pleopeltis pleopeltifolia }\end{array}$ & $\begin{array}{l}\text { Eucalyptus sp.(Eucalipto) } \\
\text { Tibouchina granulosa (Desr.) } \\
\text { Cogn. (Quaresmeira) } \\
\text { Diospyros kaki (Caqui) } \\
\text { P. rigida (Angico) }\end{array}$ & $\begin{array}{l}1-5 \\
6-10 \\
6-10 \\
6-10\end{array}$ & $\begin{array}{l}\mathrm{FB}, \mathrm{FM}, \\
\mathrm{CP}\end{array}$ & HLF \\
\hline $\begin{array}{l}\text { POLYPODIACEAE } \\
\text { Pleopeltis squalida }\end{array}$ & $\begin{array}{l}\text { P. rigida (Angico) } \\
\text { J. mimosifolia (Jacarandá) }\end{array}$ & $\begin{array}{l}6-10 \\
6-10\end{array}$ & $\mathrm{FM}, \mathrm{CP}$ & HLV \\
\hline
\end{tabular}

*Tamanho das populações de epífitos por espécie de forófito, expresso como um intervalo médio de número de indivíduos. Foram consideradas categorias de cinco indivíduos (1-5, 6-10, 11-15, 16-20, >20), sendo registrados em número absoluto apenas registros únicos (1), e sendo tratada cada "touceira" contínua como um indivíduo distinto.

fuste (fuste médio e copa), sendo apenas cinco exclusivas do fuste médio. Segundo ROGALSKI \& ZANIN (2003), as espécies que ocorrem na parte inferior do tronco são, possivelmente, as que toleram ambientes mais úmidos e sombreados, pois requerem condições ambientais semelhantes àquelas encontradas no solo. A riqueza de espécies no fuste alto e copa pode ser atribuída à maior disponibilidade e qualidade de substrato (bifurcação, ramos horizontais e acúmulo de matéria orgânica) para a fixação de epífitos (TERSTEEGE \& CORNELISSEN, 1989).

As epífitas vasculares compreendem uma grande diversidade nas matas primárias do Rio Grande do Sul, porém a vegetação do campus universitário é um resíduo de floresta secundária, formada por grande número de espécies exóticas, principalmente eucalipto. Já nas praças e no parque da cidade, apesar de muito arborizados, a quantidade de epífitas é grande e a diversidade específica é pequena, o que já é esperado para uma área urbana. Isso é resultado das alterações desencadeadas por causa da ação do ser humano na natureza e que foi intensificada no último século. A degradação de habitats pode ser considerada o principal processo que leva à perda de espécies. Essa pobreza de epífitos vasculares na zona urbana também foi relatada nos trabalhos de BRUSTULIN \& SCHMITT (2008).

Com relação às categorias ecológicas registradas, a maioria das espécies é classificada como holoepífita verdadeira (seis espécies) ou holoepífita facultativa (seis espécies). Padrão semelhante também foi registrado nos trabalhos de KERSTEN \& SILVA (2001), GERALDINO et al., (2010), KERSTEN \& KUNIYOSHI, (2009), GONÇALVES \& WAECHTER (2003), FABRICANTE et al. (2007) e
DETTKE et al. (2008). Apenas duas espécies registradas são consideradas hemiepífitas secundárias. Não foram registradas hemiepífitas primárias no presente estudo.

Segundo RIDLEY (2006), as espécies são capazes de suportar certa variedade de fatores físicos, temperatura, umidade e conseguem teoricamente, viver em qualquer ambiente em que os limites de tolerância fossem satisfeitos. Entretanto cada espécie irá abranger uma área menor do que poderia em função das relações multidimensionais com o meio.

A importância ecológica do epifitismo consiste na manutenção da diversidade biológica e no equilíbrio interativo estas espécies proporcionam recursos alimentares (frutos, néctar, pólen, água) e microambientes especializados para a fauna do dossel (WAECHTER, 1992). As epífitas são bons indicadores ecológicos, registrando tanto a qualidade e estágio dos ecossistemas quanto às variações ambientais naturais (TRIANA-MORENO et al., 2003).

As comunidades de epífitas vasculares têm sido utilizadas como bioindicadoras das mudanças climáticas, poluição e danos aos ecossistemas (RICHTER, 1991 apud DETTKE et al., 2008). Estudos em várias regiões do globo têm demonstrado que a abundância, riqueza e estrutura das comunidades de epífitas vasculares mostram importantes modificações de acordo com o grau de interferência humana (BARTHLOTT et al., 2001).

As epífitas vasculares vêm sofrendo grande exploração antrópica principalmente as das famílias Orchidaceae e Bromeliaceae, devido ao seu potencial econômico e ornamental, devido à exuberância de suas flores perfeitas e suas cores delicadas. Como sua multiplicação por 
vias naturais de propagação é lenta, algumas espécies correm o risco de entrar em extinção (ALTAFIN et al ., 2003; BRUSTULIN \& SCHMITT, 2008). Uma das espécies registradas neste trabalho está na lista de espécies ameaçadas de extinção no Brasil que é a $A$. recurvata (Secretaria Estadual do meio Ambiente., 2009) Também destaca-se a ocorrência de $R$. adiantiformis (samambaia-preta), espécie bastante utilizada na confecção de arranjos florais em todo o mundo. No sul do Brasil, a mesma vinha sofrendo um extrativismo exagerado nas últimas décadas e, para que houvesse um controle da coleta dessa espécie, foi criada legislação limitando sua retirada da natureza (SOUZA et al., 2008).

Esta planta exibe grande plasticidade ecológica, ocorrendo em diferentes ecossistemas, como restingas, rochedos e florestas em diferentes estádios sucessionais (iniciais, médios e avançados) e apresentando-se nas formas biológicas: terrestre, rupestre e epifítica (SENNA \& WAECHTER, 1997). A samambaia-preta ocorre na floresta nativa no estágio inicial de regeneração, ou seja, na capoeira.

Tanto $A$. recurvata como $R$. adiantiformis possuem uma única população registrada no campus, cada uma com poucos indivíduos (Tabela 1).

Considerando todas as espécies estudadas nota-se que elas são comuns no ambiente epifítico no Sul e Sudeste do Brasil, porém se compararmos o estudo presente com o realizado na cidade de Passo Fundo (BUZATTO et al., 2008), há algumas espécies registradas somente no presente estudo, que são $C$. flexuosa, $M$. deliciosa, $P$. bipinnatifidum, P. pleopeltifolia e $R$. adiantiformis.

$\mathrm{O}$ reduzido número de espécies em relação aos outros estudos realizados no estado Rio Grande do Sul (BUZATTO et al., 2008; BERNARDI \& BUDKE, 2009; GONÇALVES \& WAECHTER, 2002) atribui- se ao fato de se tratar de uma área urbana pouco similar aos habitats naturais das espécies em estudo. A presença dessas espécies no ambiente de estudo demonstra que essas espécies de epífitas vasculares são bastante tolerantes a impactos de antropização.

Algumas espécies arbóreas encontradas na área de estudo possuem uma arquitetura que não propicia o epifitismo vascular sendo a maioria destes membros da família Myrtaceae. Árvores de ritidoma áspero ou rugoso mostraram-se mais adequadas ao epifitismo vascular. Como a formação florestal do campus da universidade é composta principalmente por Eucaliptus spp. e Corymbia $s p p$. que são espécies menos propícias à ocupação por epífitos e o ambiente urbano do município apresenta pequena diversidade de espécies arbóreas, a baixa quantidade de espécies de epífitos registrada nestes locais já era esperada. Outro motivo para baixa quantidade de indivíduos no campus e pequeno número de espécies epifíticas pode ser a idade dos forófitos, que é um fator importante para determinação do estabelecimento da comunidade epifítica. A formação florestal do campus é considerada jovem, pois a área era anteriormente for- mada por pastagens para atividade pecuária e áreas de cultivo, e recentemente iniciou-se a regeneração natural do componente arbóreo, quando da implantação do campus universitário, no ano de 2006. Os usos anteriores da área também podem ter contribuído para a baixa diversidade encontrada.

\section{Conclusão}

A presença de espécies de amplo espectro biológico nos locais de estudo (Campyloneurum nitidum, L. lumbricoides, P. pleopleltifolia, M. squamulosa, P. hirsutissima, $P$. squalida, $T$. recurvata e $T$. stricta) e o pequeno número de espécies registrado (14) são compatíveis com o esperado na maioria dos ambientes urbanos, onde a baixa diversidade e idade de forófitos, bem como a influência das atividades humanas (poluição, manejo) interferem negativamente no estabelecimento de epífitos. Entretanto, o registro de uma espécie rara no estado (Aechmea recurvata) demonstra a importância ecológica de fragmentos florestais e de áreas verdes no ambiente urbano na conservação de espécies vegetais. Com base nas observações realizadas, constatou-se que a proteção das áreas estudadas, associada com a manutenção de árvores mais velhas, é fundamental para a conservação das comunidades epifíticas urbanas, as quais podem funcionar como ponte entre as comunidades epifíticas do entorno, permitindo algum fluxo gênico e, desse modo, contribuindo com a conservação das espécies da região.

\section{Agradecimentos:}

Os autores agradecem ao Programa Institucional de Voluntários em Iniciação Científica (PIVIC-UFSM) pelo apoio concedido.

\section{Referências}

ALTAFIN, V. J.; MENEZES, M. O.; LIMA, R. R.; PITOMBO, L. M. Semeadura in vitro de orquídeas para propagação massal. São Paulo, Boletim técnico n. 7, p. 1 - 14, 2003.

ARDENGHI, L. Caboclos, ervateiros e coronéis: luta e resistência em Palmeira das Missões- RS. Dissertação (mestrado) - Universidade de Passo Fundo, p. 2 - 209, 2003.

BARTHLOTT, W.; SCHMIT-NEUERBURG, V.; NIEDER, J.; ENGWALD, S. Diversity and abundance of vascular epiphytes: a comparison of secondary vegetation and primary montane rain forest in the Venezuelan Andes. Plant Ecology, p. 145 - 156, 2001. 
BATAGHIN, F. A.; FIORI, A.; TOPPA, R. H. Efeito de borda sobre epífitos vasculares em Floresta Ombrófila Mista, Rio Grande do Sul, Brasil. O mundo da saúde, v. 32, p. 329 - 338, 2008.

BAUER, D.; WAECHTER, J. L. Sinopse taxonômica de Cactaceae epifíticas no Rio Grande do Sul, Brasil. Acta Botanica Brasilica, v. 20, n. 1, p. 225 - 239. 2006.

BENNET, B. C. Patchness, diversity, and abundance relationships of vascular ephiphytes. Selbyana, v. 9, p. $70-75,1986$.

BENZING, D. H. Vascular epiphytes. Cambridge University Press. Cambridge, 1990.

BERNARDI, S.; BUDKE, J. C. Estrutura da sinúsia epifítica e efeito de borda em uma área de transição entre floresta estacional semidecídua e floresta ombrófila mista. Floresta, Curitiba, PR, v. 40, n. 1., p. 81 - 92 p. 2009.

BRUSTULIN, J.; SCHMITT, J. L. Composição Florística, Distribuição Vertical e Floração de Orquídeas Epifíticas em Três Parques Municipais do Estado do Rio Grande do Sul, Brasil. Botânica $N^{\circ}$ 59: São Leopoldo: Instituto Anchietano de Pesquisas, p. 143 - 158, 2008.

BUZATTO, C. R.; SEVERO, B. M. A.; WAECHTER, J. L. Composição florística e distribuição ecológica de epífitos vasculares na Floresta Nacional de Passo Fundo, Rio Grande do Sul, Porto Alegre, IHERINGIA, Série. Botânica, v. 63, p. 231 - 239, 2008.

BUZATTO, R.; FREITAS, E. M.; SILVA, A. P. M.; LIMA, L. F. P. Levantamento florístico das Orchidaceae ocorrentes na Fazenda São Maximiano, Município de Guaíba, Rio Grande do Sul. Revista Brasileira de Biociências, Porto Alegre, v. 5, n. 2 - 3, p. 19 - 25, 2007.

COSTA, V. L. Estudo Fitossociológico do componente arbóreo de um remanescente florestal em Palmeira das Missões, RS, Brasil, p. 1- 26, 2010.

DETTKE, G. A.; ORFRINI, A. C.; MILANEZEGUTIERRE, M. A. Composição florística e distribuição de epífitas vasculares em um remanescente alterado de Floresta Estacional Semidecidual no Paraná, Brasil. Rodriguésia, v. 59, n. 4, p. 859 - 872, 2008.

DISLICH, R. Florística e estrutura do componente epifítico vascular da Reserva da Cidade
Universitária "Armando de Salles Oliveira", São Paulo, Brasil. Tese (Mestrado em Ecologia) - Instituto de Biociências, Universidade de São Paulo. p. 1 - 183, 1996.

FABRICANTE, J.R.; SANTOS, F.S.; GONÇALVES, I.O.; FERREIRA, J.C.; MICHELIN, A.

Caracterização Florística do Componente Epifítico Vascular Ocorrente nas Formações Florestais da Fazenda Noiva da Colina, Município de Borebi (SP). Revista Salusvita (Online), v. 26, p. 7-20, 2007.

FIDALGO, O.; BONONI, V. L. R., (Coords.). Técnicas de coleta, preservação e herborização de material botânico. São Paulo: Instituto de Botânica, 1984.

FILGUEIRAS, T. S.; NOGUEIRA, P. E.; BROCHADO, A. L.; GUALA II, G. F. Caminhamento - Um método expedito para levantamentos qualitativos. Cadernos de Geociências, Rio de Janeiro, v. 12, p. $39-43,1994$.

GERALDINO, H.C.L.; CAXAMBÚ, M.G.; SOUZA, D.C. Composição florística e estrutura da comunidade de epífitas vasculares em uma área de ecótono em Campo Mourão, PR, Brasil. Acta Botanica Brasilica, v. 24, n. 2, p. 469 - 482, 2010.

GIONGO, C.; WAECHTER, J.L. Composicão florística e estrutura comunitária de epífitos vasculares em uma floresta de galeria na Depressão Central do Rio Grande do Sul. Revista Brasileira de Botânica, v. 27, p. 563 - 572, 2004.

GONÇALVES, C.N.; WAECHTER, J. L. Aspectos florísticos e ecológicos de epífitos vasculares sobre figueiras isoladas no norte da planície costeira do Rio Grande do Sul. Acta Botanica Brasilica, v. 17, n. 1, p. 89 - 100, 2003.

KERSTEN, R. A. Epífitas vasculares - Histórico, participação taxonômica e aspectos relevantes, com ênfase na Mata Atlântica. Curitiba, PR. Hoehnea, v. 37, n. 1, p. 9 - 38, 2010.

KERSTEN, R. A.; KUNIYOSHI, Y. S. Conservação das Florestas na Bacia do Alto Iguaçu, Paraná Avaliação da comunidade de epífitas vasculares em diferentes estágios serais. Floresta, Curitiba, PR, v. 39, n. 1, p. 51 - 66, 2009.

KERSTEN, R. A.; SILVA, S. M. Composição florística e estrutura do componente epifítico vascular em floresta da planície litorânea na Ilha do Mel, Paraná, Brasil. Revista Brasileira de Botânica, São Paulo, v. 24, n. 2, p. 213 - 226, 2001. 
LONGHI, S. J. Agrupamento e análise fitossociológica de comunidades florestais na sub-bacia hidrográfica do Rio Passo Fundo-RS. Curitiba, PR, p. 1 - 215, 1997.

RIDLEY, M. Evolução. 3. ed. Porto Alegre: Artmed, 2006.

ROGALSKI, J.M.M.; ZANIN, E.M. Composição florística de epífitos vasculares no estreito de Augusto César, Floresta Estacional Decidual do Rio Uruguai, RS, Brasil. Revista Brasileira de Botânica, v. 26, n. 4, p. 551 - 556, 2003.

SCIPIONI, M. C.; FINGER, C. A. G.; CANTARELLI, E. B.; DENARDI, L.; MEYER, E. A. Fitossociologia em fragmento florestal no noroeste do estado do Rio Grande do Sul. Ciência Florestal, Santa Maria, v. 21, n. 3, p. 409 - 419, 2011.

\section{SECRETARIA ESTADUAL DO MEIO AMBIENTE.} Fundação Zoobotânica do Rio Grande do Sul. Museu de Ciências Naturais. Jardim Botânico. 2009. Laudo de Cobertura Vegetal e Mapeamento das Principais Manchas de Vegetação do Centro de Atendimento Sócio Educativo Padre Cacique CASE, Fundação de Atendimento Sócio Educativo - FASE. 1-20p.

SENNA, R. M.; WAECHTER, J. L. Pteridófitas de uma floresta com araucária. "1.Formas biológicas e padrões de distribuição geográfica". Iheringia, Série Botânica, v. 48, p. 41 - 58. 1997.

SOUZA, G. C.; PEREIRA, F.M.; KUBO, R. R. O extrativismo da samambaia-preta no Rio Grande do Sul. Editora da UFRGS, p. 1 - 23, 2008.

TERSTEEGE, H.; CORNELISSEN, J. H. C. Distribution and Ecology of vascular epiphytes in Lowland Rain Forest of Guyana. Biotropica, v. 21, p. 331 - 339, 1989.

\section{TRIANA-MORENO, L. A.; GARZÓN-VENEGAS,} N. J.; SÁNCHEZ-ZAMBRANO, J.; VARGAS, O. Epífitas vasculares como indicadores de regeneración enbosques intervenidos de la amazonía Colombiana. Acta Biológica Colombiana, Bogotá, v. 8, p. 31 - 42, 2003.

VACCARO, S.; LONGHI, S. J. Análise fitossociológica de algumas áreas remanescentes da Floresta do Alto Uruguai, entre os Rios Ijuí e Turvo, no Rio Grande do Sul. Ciência Florestal, Santa Maria, v. 5, n. 1, p. 33 - 53, 1995.

WAECHTER, J. L. O epifitismo vascular na Planície
Costeira do Rio Grande do Sul. Tese de Doutorado, Universidade Federal de São Carlos, São Carlos, 1992.

WAECHTER, J. L. Epifitismo vascular em uma floresta de restinga do Brasil subtropical. Ciência e Natura, Santa Maria, v. 20, p. 43 - 66, 1998. 